\title{
L'HISTOIRE DE LA PESTE EN EUROPE AU REGARD DE LA PANDEMIE DE COVID19
}

\section{The history of the plague in Europe in the light of the Covid19 pandemic}

\author{
Prof. Dr. Jean-Claude Schmitt \\ Directeur d'étude, EHESS \\ École des Hautes Études en Sciences Sociales, Paris \\ ORCID: https://orcid.org/0000-0001-6237-8293 \\ E-mail: jcsvialas@gmail.com
}

Recebido em: 09/09/2020

Aprovado em: 10/10/2020

\begin{abstract}
Resumé: La pandémie de Covid 19 à partir de janvier 2020 - depuis la Chine vers le reste de l'Asie, puis l'Europe et l'Afrique, et enfin les deux Amériques -, n'est pas sans rappeler des épidémies du passé, souvent bien plus meurtrières encore, en premier lieu celles de la peste (qui emporta le tiers de la population européenne en 1348). Trois épidémies de peste ont frappé l'Europe à travers l'histoire : la Peste de Justinien (541-770), la Peste Noire (1348-1352, suivie de nombreuses récidives jusqu'en 1720) et la peste de Chine (qui n'a touché en fait que les ports européens et américains, entre 1850 et 1940). La peste, par ses agressions ou ses retraits, a une valeur systémique pour le «long Moyen Âge » qui commence dans l'Antiquité tardive et se poursuit jusqu'au XVIIIe siècle : par ses assauts répétés tout au long de cette période, mais aussi par ses retraits comme entre l'époque de Charlemagne et le XIVe siècle ; cet âge «sans peste » correspond à la phase du plus grand essor des campagnes médiévales. Au contraire, quand la peste est de retour entre le XIVe et le XVIIe siècle, elle est un des facteurs décisifs d'une longue stagnation démographique. Jamais la cause véritable de la peste (qu'on attribuait à la corruption de l'air ou à un châtiment de Dieu) n'a été reconnue tout au long de ces siècles. Pourtant on observe dès la fin du Moyen Âge une progression des conceptions « contagionistes » et nonofficielles qui anticipent sur la découverte du bacille de la peste par Alexandre Yersin en 1894, en même temps que du rôle des puces et des rats. La peste a suscité des comportements de toutes natures, qui évoquent parfois les mesures prises aujourd'hui pour freiner ou empêcher la progression de l'épidémie (par exemple la quarantaine). Elle a nourri de nouveaux élans de piété et aussi la recherche de boucs-émissaires dont les communautés juives furent les premières victimes. Sur le plan culturel, elle suscita de brillants témoignages littéraires (tel le Decameron de Giovanni Boccacio), mais on ne peut pas lui attribuer la naissance de l'art macabre, car celui-ci lui est antérieur.
\end{abstract}

Mots-clés: Peste, Europe Macabre, Antijudaisme, Contagion Démographie, Zoonose.

Abstract:The Covid 19 pandemic from January 2020 - from China to the rest of Asia, then Europe and Africa, and finally the two Americas -, is reminiscent of epidemics of the past, often much more deadly still, in the first place those of the plague (which carried away a third of the European population in 1348). Three plague epidemics have struck Europe throughout history: the Plague of Justinian (541-770), the Black Death (1348-1352, followed by numerous recurrences until 1720) and the Plague of China (which outside Asia only affected European and American ports between 1850 and 1940). The plague, by its aggressions or its withdrawals, has a systemic value for the "long Middle Ages" (which begins in late Antiquity and continues until the 18th century), as well by its repeated assaults throughout this period, as by its withdrawal between the time of Charlemagne and the fourteenth century; this "plague-free" age corresponds to the phase of the greatest growth of the medieval times. On the contrary, when the plague returned between the 14th and 17th centuries, it was one of the decisive factors (beside permanent wars) in a long demographic stagnation. The true cause of the plague (which was officially attributed to the corruption of the air or to a punishment from God) has never been recognized throughout these centuries. However, from the end of the Middle Ages we can observe a progression of "contagionist" and unofficial conceptions which anticipate the discovery of the plague bacillus by Alexandre Yersin in 1894, together with the role of fleas and rats. The plague has given rise to behavior of all kinds, which sometimes evokes the measures taken today to slow down or prevent the progression of the epidemic (for instance the quarantine). It fed new impulses of piety and also the search for scapegoats, of which the Jewish communities were the first victims. Culturally, it aroused brilliant literary testimonies (such as Giovanni Boccacio's Decameron), but we cannot attribute to it the birth of macabre art, because it predates it.

Keywords: Plague, Europe Macabre, Antijudaism, Contagion Demography Zoonosis. 
L'année 2020 a donné l'occasion à la planète entière, dès le mois de janvier, de faire l'expérience inattendue et sans précédent à certains égards d'une pandémie virale ayant touché successivement en un temps record l'Asie (la Chine, berceau de l'épidémie, puis l'Inde plus durement encore), l'Europe (celle du Sud plus que celle du Nord), l'Afrique (dans une moindre mesure) et surtout les deux Amériques du Nord et du Sud où elle ne cesse de faire de terribles ravages au moment où j'écris. ${ }^{1}$ Cette terrible épreuve, à l'échelle mondiale, a des conséquences dramatiques sur l'économie et la société, alors même que le nombre des morts (plus de 800000 dans le monde, dont 170000 rien qu'aux USA et 120000 au Brésil) est resté relativement modeste, si on le compare aux conséquences démographiques d'autres épidémies, comme la «grippe espagnole » de 1918-1919 (50 millions de morts). Elle a aussi des conséquences sur les comportements quotidiens des populations, en imposant des "gestes barrières" inédits par rapport aux traditions culturelles de nombreux pays: les embrassades sont prohibées, le port du masque dans les lieux publics et sur les lieux de travail devient obligatoire. Dans une grande partie de l'Europe notamment, la contrainte du «confinement» chez soi, sous peine de pénalités, est durement ressentie. S'y ajoute dans certains cas un retour à la pratique ancienne de la quarantaine, transformée en une «quatorzaine» adaptée au temps d'incubation du virus. Dans les pays les plus développés, l'épidémie a pris les gouvernants comme les populations de court et a révélé une grande impréparation. Force est de reconnaître que les risques accrus de zoonose ont été négligés, alors même que les milieux scientifiques et les organisations non-gouvernementales alertaient depuis des années sur les dangers d'une intensification des relations entre les hommes et des animaux sauvages, comme les chauves-souris et les pangolins. On imaginait à tort que de telles épidémies étaient réservées aux «autres» (les Africains confrontés à Ebola) ou aux siècles passés: la "grippe espagnole » au lendemain de la première Guerre mondiale, le choléra qui fit en Europe des millions de morts vers 1830-1832, la variole et la rougeole que les Européens importèrent au XVIe siècle dans le Nouveau Monde, avec les conséquences catastrophiques que l'on sait pour les populations amérindiennes. Et d'oublier jusqu'à l'hécatombe annuelle des grippes saisonnières, bien plus importante en définitive que celle du Covid19. 
Parmi les épidémies passées, celles de la peste, qui a sévi en Europe jusqu'en 1720, mais qui reste une menace dans certains pays comme Madagascar, occupe dans l'imaginaire collectif une place privilégiée. Son nom même est communément érigé au rang de métaphore du mal absolu, comme lorsqu' Albert Camus évoque en 1947, au sortir de la Seconde Guerre Mondiale, une épidémie fictive et non datée de peste à Oran, pour signifier en filigrane les ravages de la «peste brune » nazie et vichyste. L'historien constate pour sa part que la peste et ses retours ont concerné, en dépit d'interruptions durables, tout le « long Moyen Âge $»^{2}$ allant de l'Antiquité tardive (VIe siècle) jusqu'à l'aube de la révolution industrielle (XVIIIe siècle) : à n'en juger encore que par ces bornes chronologiques, on voit déjà que la peste revêt une valeur systémique pour les sociétés préindustrielles d'Europe, durant cet « Ancien régime » pluriséculaire qu'elle invite à envisager dans toutes ses composantes, non seulement sanitaires, mais démographiques, économiques, sociales, politiques, culturelles. ${ }^{3}$

\section{Préliminaires}

On distingue habituellement trois grandes épidémies de peste ayant inégalement frappé l'Europe:

1) La «Peste de Justinien », du nom de l'empereur qui, au milieu du VIe siècle, entreprit de reconquérir sur les Goths l'Italie du Nord et qui promulgua le célèbre code de droit romain portant son nom. Il s'agit d'une peste bubonique qui, importée d'Orient, sévit dans l'empire byzantin à partir de 541 puis gagna l'Italie du Nord (Ravenne), la vallée du Rhône (de Marseille à Lyon) et l'Italie du Sud (Naples). Elle connut une quinzaine de poussées, particulièrement en 558-561 et en 590 à Rome, où le pape Grégoire le Grand l'aurait repoussée en conduisant une procession jusqu'au Mausolée d'Hadrien, au sommet duquel serait apparu miraculeusement l'archange Saint Michel : d'où le nom de «Château Saint-Ange » qu'il porte depuis. Cette épidémie eut de lourdes conséquences en affaiblissant l'empire et en facilitant ainsi l'expansion de l'islam au siècle suivant. Elle se prolongea par intermittence jusqu'en 767.

2) La "Peste noire » (Black Death), qui surgit en Europe en 1347 - 1348, puis fait retour en moyenne tous les cinq à dix ans jusqu'en 1720 en Europe (Peste de Marseille) et en 1841 en Afrique du Nord. Elle aussi vint de Chine, transportée vers l'Occident par 
les Mongols et grâce aux échanges de tous ordres dont s'animait la Route de la Soie. Elle trouva un relai favorable dans le comptoir génois de Caffa (Crimée) - assiégé par les Mongols - avant de gagner Constantinople, puis les ports italiens et celui de Marseille où elle arriva le 1 novembre 1347. Elle présentait une forme principalement bubonique, mais aussi pulmonaire. Les poussées pesteuses se succédèrent pendant trois siècles, mais leur intensité diminua progressivement. Après la première flambée, la plus meurtrière, de 1348 à 1352, qui traversa la quasi-totalité de l'Europe pour atteindre finalement Moscou, la peste fut de retour en 1363, en 1374, en 1383, etc., et pareillement au cours des XVIe et XVIIe siècles. Dans le seul royaume de France, on compte 26 poussées principales et 11 poussées secondaires entre le XIVe et le XVIIe siècle, soit une tous les huit ans. A l'exception de 1348, les plus meurtrières eurent lieu au XVIIe siècle : en 1606, en 1628-1629 (année où le royaume aurait perdu 1, 6 million d'habitants, soit près de $10 \%$ de sa population), en 1668-1670 enfin. Après quoi, la peste ne fit plus parler d'elle, avant de revenir en force, une dernière fois, en 1720.

Notons cependant que jamais, entre la fin du XVe siècle et le début du XVIIIe siècle, la peste, contrairement par exemple à la variole, n'a traversé l'Atlantique. Les raisons, sans doute environnementales, en sont mal élucidées. Dans le cas contraire, la «guerre microbienne » livrée aux populations amérindiennes eût été plus dramatique encore s'il se peut.

De toutes ces données, il faut retenir que la peste ne vient jamais seule : elle est précédée ou accompagnée par des disettes, l'instabilité du climat (des intempéries, des précipitations ou au contraire de longues périodes de sécheresse), des épizooties qui ravagent le bétail, des guerres (avec les passages des troupes qui favorisent la diffusion du mal). La faim, la guerre et la peste sont les trois fléaux indissociables contre lesquels les populations chrétiennes implorent du même mouvement la protection divine. Ainsi, la Peste Noire de 1348 a-t-elle été précédée en 1315-1318 par une terrible famine, due aux mauvaises récoltes, qui avaient elles-mêmes, vraisemblablement, des causes climatiques. $^{4}$ Famine et peste s'inscrivent plus généralement encore dans un retournement de la conjoncture sensible dès la fin du XIIIe siècle et qui sévit jusque vers 1470 (le «petit âge de glace »), et même au-delà aux XVIe - XVIIe siècle : le cycle dramatique de la stagnation démographique, des mauvaises récoltes, de la famine et des épidémies, auquel s'ajoute la guerre permanente (Guerre de Cent Ans, Guerres de 
Religions, Guerre de Trente Ans), explique, par-delà les effets catastrophiques de la peste seule, que l'Europe se retrouve au XVIIe siècle avec une population voisine de ce qu'elle était vers 1300. La France, par exemple, n’a jamais dépassé pendant toute cette période le chiffre de dix-sept à vingt millions d'habitants.

Cette longue période de stagnation et de crise, dont les récurrences de la peste sont l'un des facteurs les plus emblématiques, contraste avec la période précédente, marquée par un essor rapide de toutes les forces matérielles et humaines entre la fin de la Peste de Justinien (VIIIe siècle) et la Peste Noire (XIVe siècle). On estime que la population européenne a pu tripler entre 800 (l'époque de Charlemagne) et 1348. Des facteurs climatiques massifs, liés à l'irradiation solaire, aux émissions volcaniques (intenses entre 1167 et 1284), aux oscillations des masses d'air des océans Pacifique et Atlantique (le phénomène El Ningo), ont permis pendant quatre à cinq siècles un réchauffement du climat et une modification de la pluviosité que l'on mesure grâce à la dendrochronologie (lecture des tree-rings ou cernes des arbres), aux carottages des zones glaciaires ou encore aux crues du Nil (connues annuellement de 641 à 1469). Ces modifications climatiques ont favorisé l'extension des cultures vivrières et par voie de conséquence l'essor démographique d'une société presque exclusivement rurale. Au contraire, la population, vers 1450 , ne serait plus que la moitié de ce qu'elle était avant la Peste Noire 5

3) La Peste de Chine: partie du Yunnan, elle a sévit entre 1850 et 1940 en Asie (notamment en Inde où elle fit 10 millions de mort) et à Madagascar. Elle n'a atteint que marginalement le monde occidental, en se limitant à certains ports d'Europe et d'Amérique. Mais son rôle n'en est pas moins important pour l'histoire de la peste puisqu'elle permit à Alexandre Yersin de découvrir à Hong-Kong en 1894 le bacille qui en est la cause, ainsi que le rôle des puces et des rats dans sa transmission.

\section{Interprétations}

Un mot d'abord du mot «peste» : il vient du latin pestis qui, loin de désigner originellement une maladie particulière, désigne toute sorte de fléau. Il en va exactement de même du mot grec leimos qu'utilise Thucydide (430-426 BC) pour 
décrire minutieusement le «fléau » qui a frappé Athènes vingt-cinq ans plus tôt ${ }^{6}$ : une épidémie catastrophique qui survint en même temps que la guerre du Péloponèse et que les érudits appelèrent à tort «la Peste d'Athènes », alors qu'il s'agissait vraisemblablement du typhus, venu d'Ethiopie par la Syrie et l'Asie Mineure. Toujours est-il que cet évènement donna lieu, de la part du grand historien grec à une description aussi dramatique que détaillée dont se souviendront bien plus tard les auteurs voulant dépeindre la peste véritable. Les textes médiévaux utilisent quant à eux, pour désigner la Peste Noire, les mots génériques mors, morbus, mortalitas ou leurs équivalents vernaculaires (tel mortalité en moyen français). Mais à partir de 1348, les mots peste et pestilence tendent à prendre un sens spécifique, en ne désignant plus que la peste véritable.

Dans l'Antiquité tardive comme au Moyen Âge et à l'Epoque moderne, la peste fut attribuée en premier lieu à la corruption de l'air en même temps qu'à un châtiment divin que les hommes auraient mérité par leurs péchés. De telles explications faisaient bon ménage avec les principes fondamentaux de la médecine traditionnelle, qui reposait sur la notion d'équilibre interne (entre les humeurs, le chaud et le froid, l'humide et le $\mathrm{sec}$ ) et externe (les correspondances entre le microcosme et le macrocosme) du corps humain : c'est ainsi que le tempérament sanguin (chaud et humide) passait pour rendre plus vulnérable à la peste que les tempéraments colérique, flegmatique ou mélancolique. Cependant, dès la fin du Moyen Âge, d'autres conceptions se font jour, qui incluent la possibilité d'une contagion entre les hommes. En 1626, le jésuite mathématicien Athanase Kircher, dont le savoir est encyclopédique, avance la notion de « contagium vivum » pour suggérer que quelque « animalcule » observé par lui dans son microscope pourrait être responsable de la peste. Ainsi les conceptions «contagionistes » ont-elles peu à peu progressé, mais sans détrôner pour autant les conceptions traditionnelles (corruption de l'air et châtiment divin) défendues par les autorités médicales, civiles ou religieuses. Ces nouvelles conceptions anticipaient en un certain sens sur les découvertes de Pasteur et, plus spécifiquement, de Yersin. Mais il faut souligner que jamais personne, avant ce dernier, n'a mis en cause le rôle des puces et des rats : ces insectes et rongeurs étaient bien trop communs et familiers pour que les hommes, habitués à piéger les uns et à s'épouiller des autres, pussent les soupçonner de jouer un rôle aussi morbide! 
La science moderne a donc permis d'identifier enfin la cause du mal dont on avait, empiriquement, commencé à se protéger dans les siècles passés. On distingue deux formes de peste : la peste bubonique, la plus fréquente, due à la morsure d'une puce (ou d'un pou) transportée par le rat noir (ratus ratus). Cette forme pesteuse, caractérisée par l'apparition de bubons à l'aine ou aux aisselles, puis de charbons cutanés sur tout le corps, ainsi que par de fortes fièvres et des hallucinations, offre néanmoins des chances de guérison. Il n'est pas certain que l'élimination du rat noir par le rat gris au XVIIIe siècle ait joué un rôle significatif dans la disparition de la peste en Europe. L'autre forme de la peste est la peste pulmonaire, qui se transmet directement d'homme à homme et qui est mortelle dans tous les cas.

\section{La peste en Europe de 1348 à 1670}

De 1348 à 1352, la Peste Noire a recouvert l'Europe entière de manière fulgurante, pour atteindre Moscou en quatre ans, en ne laissant indemnes derrière elle que de rares régions : des isolats dans les Balkans (parce qu'elle est passée par la mer), dans certains massifs montagneux (comme les Pyrénées et le Massif Central en France) ou dans l'arrière-pays de certaines villes, comme Bruges, qui fut au contraire durement touchée. La chance joua aussi son rôle : un bateau prêt à lever l'ancre à destination de l'Islande resta au port parce que tout son équipage avait succombé; sauvée provisoirement du fléau, la grande île du Nord attendit 1402 pour subir la peste pour la première fois.

La progression de l'épidémie ne dépassa pas en moyenne $2 \mathrm{~km}$ par jour : c'est peu, comparé à la distance parcourue en une journée de marche à pied ou à plus forte raison à cheval, ou à la vitesse avec laquelle on peut descente une rivière à bord d'une gabarre. Mais il faut compter avec les conditions concrètes des déplacements le long des chemins ou des voies d'eau et les chances inégales de rencontre avec d'autres voyageurs ou les populations locales. La peste se répandait plus rapidement en descendant un fleuve (par exemple la Garonne de Toulouse à Bordeaux) qu'en le remontant (à l'exemple du Rhône entre Marseille à Lyon, par où elle fit sa première percée en Europe occidentale). 


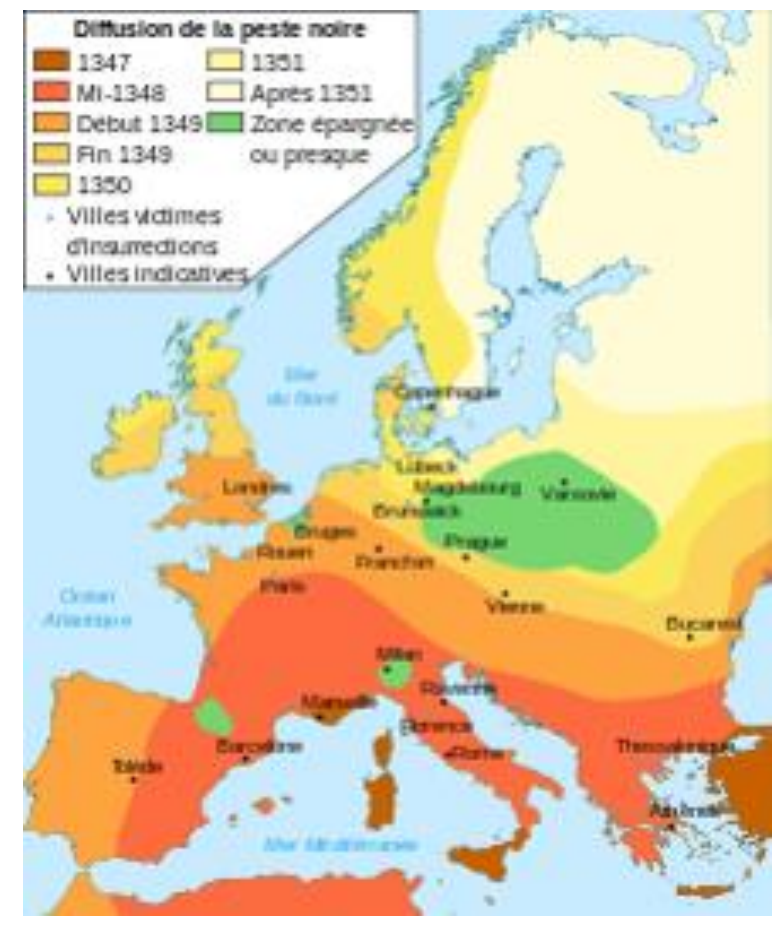

Ill. 1 : Carte de la diffusion de l'épidémie de peste en 1348-1352

Toujours est-il que l'hécatombe fut immense, au point qu'il nous est difficile de l'imaginer. Guy Bois, historien de la Normandie aux deux derniers siècles du Moyen Âge, parlait d'un «Hiroshima en Normandie $»^{7}$ : la métaphore de la bombe atomique n'est pas trop forte en effet pour nous faire prendre la mesure d'une catastrophe aussi brutale et meurtrière. Mais, faute de statistiques, nous en sommes réduits à des estimations très approximatives, en tirant le meilleur profit possible de sources fragmentaires et variées.

A défaut de recensements de la population, on dispose parfois, exceptionnellement, de données chiffrées et pluriannuelles permettant d'évaluer la même population avant et après le passage de la peste : c'est le cas (bien connu des historiens) de la paroisse de Givry, en Bourgogne, grâce à des comptes paroissiaux, qui enregistrent exceptionnellement les droits perçus par le curé sur les mariages et les sépultures durant presque toutes les années 1334 - 1357. Initialement, la paroisse comptait peut-être 2000 habitants et on y procédait annuellement à 28 ou 29 inhumations par mois. Durant les quatre mois de juillet à octobre 1348, le nombre des inhumations se monta certains jours à 24 ! La peste faucha au total environ 600 personnes, soit le tiers de la population. Les chiffres sont comparables dans la paroisse 
de Saint-Nizier de Lyon, qui comptait 3000 ou 4000 habitants avant la peste. On y enregistrait habituellement 80 à 85 inhumations par mois. Entre avril et juin 1348, on compte 900 à 1000 décès, dont ceux de 300 à 350 enfants : les pertes se montent là encore à 20 ou $30 \%$ de la population.

D'autres séries de chiffres sont également disponibles : c'est le cas du nombre des testaments passés devant notaire à l'approche de l'épidémie. A Londres, une quarantaine de testaments étaient conclus chaque année; en 1349, on en compte 360. Dans la paroisse de Saint-Germain-l'Auxerrois à Paris, on passe pareillement d'une moyenne annuelle de 1 à 4 testaments à 50 testaments dans la seule année 1348-1349. Cela en dit long, sinon des morts avérées, du moins de la peur de mourir prochainement.

Localement, d'autres séries documentaires peuvent nous renseigner, telles que des listes des « feux » (ou foyers) dépendant d'une seigneurie foncière. Par convention, les historiens estiment qu'un feu abrite cinq personnes sous son toit. En voici un exemple privilégié, qui concerne un village du Sud de la France que je connais bien ${ }^{8}$ : les paroissiens du village de Castagnols (aujourd'hui Vialas) dépendaient pour la terre qu'ils cultivaient de deux seigneurs fonciers : la seigneurie de Montclar (dont les ruines du château dominent encore le village) et le prieuré canonial de Gourdouze (établi plus haut dans la montagne sur le rebord du plateau du Lozère). Le premier seigneur a fait dresser deux listes de ses tenanciers et de leurs redevances : l'une en 1337, avant la peste (sont énumérés 54 feux, soit environ 250 habitants), et une autre en 1357, après la peste : on ne compte plus à cette date que 41 feux, soit 190 personnes environ. De son côté, le prieuré de Gourdouze comptait en sa dépendance, en 1347, à la veille du fléau, 115 feux, soit environ 550 habitants ; faute de liste de tenanciers après le passage de la peste, on ignore dans ce deuxième cas combien de personnes ont survécu, mais on peut extrapoler un chiffre probable de la liste de Montclar. Au total, la population villageoise est vraisemblablement passée d'un minimum de 900 à 1000 habitants à 450 seulement, soit une perte de $40 \%$ ! Notons cependant que ce gouffre démographique a dû se combler progressivement dans les décennies suivantes, avant de se stabiliser aux alentours de 1500 habitants tout au long des XVIe - XVIIIe siècles. ${ }^{9}$

Si l'on multiplie les observations locales, on parvient à la conclusion terrifiante que l'Europe perdit en quatre ans un bon tiers de sa population. Après quoi, les retours périodiques de la peste pendant trois siècles continuèrent de frapper les populations sans 
lui laisser jamais le répit nécessaire à un redressement durable. Mais il faut tenir compte des différences géographiques, de l'opposition entre d'une part les villes densément peuplées et plus vulnérables, et d'autre part les campagnes, surtout quand l'habitat était dispersé. Dans certaines villes, comme Venise en 1405, Milan en 1576-1577, Lyon et Digne en 1629, on observe des taux de mortalité supérieurs à $50 \%$ ! Bien des villes ont subi de ce fait un déclin durable, comme Florence, Séville, Barcelone. D’autres, il est vrai, se redressèrent rapidement, comme Londres qui passe au XVIIe siècle de 200000 à 400000 habitants.

Grandes furent aussi les différences sociales, puisque les mieux nantis avaient la possibilité de se réfugier dans des résidences campagnardes isolées, à l'exemple du groupe de sept jeunes femmes et trois jeunes gens qu'évoque Giovanni Boccacio en 1353 dans le prologue du Decameron : alors que toute la société florentine est mise à bas par le fléau, que les cadavres s'accumulent dans les rues faute de sépulture et que succombent même les porcs qui ont fouillé avec leur groin dans les hardes des victimes, une poignée insouciante d'aristocrates dans la fleur de l'âge se met à l'abri dans une villa du contado pour se raconter de plaisantes histoires... Cette fiction littéraire n'est pas loin de la réalité, puisque quelques années plus tard, en 1362, alors que la peste était de retour, Francesco Petrarca écrivit à son ami Boccacio pour l'inviter à quitter la ville avec lui.

D'autres narrations faites à vif nous permettent pareillement d'apprécier les réactions des contemporains. Gabriele de' Mussis (+ 1356), actif à Piacenza, compose en latin une Historia de Morbo où il décrit en termes dramatiques le siège de Caffa (où les Mongols auraient projeté dans la ville génoise, par-dessus les remparts, des cadavres de pestiférés) et les ravages de l'épidémie en Sicile. Plus au Nord, l'abbé de SaintMartin de Tournai, Giles Le Muisis (+ 1353), compile plusieurs chroniques très précises entre 1347 et 1351. Les miniatures qui illustrent certains manuscrits de son œuvre montrent l'accumulation des cercueils portés dans le plus grand désordre au cimetière et les massacres des juifs accusés de propager l'épidémie. 


\section{La Peste de Marseille en 1720}

Après 1670, la peste sembla déserter le royaume de France. Mais elle revint en force un demi-siècle plus tard, pour une dernière fois. Le 24 mai 1720 arrive du Levant dans le port de Marseille le Grand Saint-Antoine, qui a fait déjà escale à Tripoli, Livorno et Toulon. Le propriétaire de la cargaison, un échevin marseillais influent, a stipendié les officiers du port pour qu'ils écourtent la quarantaine de l'équipage et autorisent le déchargement rapide du navire. Mais les ballots de soie orientale descendus sur le quai sont infestés de puces porteuses de la peste. L'épidémie se répand dans la ville, d'abord lentement, puis elle se déclare le 28 juin. Avec les fortes chaleurs de l'été et à la suite de pluies torrentielles, elle explose le 21 juillet. C'est la panique : 10000 personnes quittent la ville et s'enfuient en Provence, où l'épidémie se répand. Un cordon sanitaire est mis en place le 4 août autour de la ville, mais de nombreux fugitifs parviennent à le franchir. En ville, les maisons contaminées sont fermées et enfumées, et leur porte marquée d'une croix rouge. En juillet, on compte cent morts par jour, que les « corbeaux », qui sont souvent des forçats libérés à cette seule fin, doivent enlever pour les ensevelir, au risque d'être eux-mêmes contaminés. En août, le nombre quotidien des victimes atteint 400 par jour, en septembre il est de 1000. Au total, la peste de 1720 aura tué dans la région 120000 personnes, dont 50000 à Marseille même.

Ce retour dramatique de l'épidémie a eu dans tout le royaume et au-delà un fort retentissement. Le roi Louis XV envoie une délégation de médecins, conduite par le docteur Chicoyneau, doyen de la faculté de médecine de Montpellier. Par précaution, il revêt le costume protecteur mis au point au siècle précédent par le médecin du roi Louis XIII Charles Delorme, et qui se distingue notamment par son long bec contenant des épices, du tabac et de la poudre. Une gravure allemande nous dévoile cet étrange accoutrement, signe du retentissement lointain de la Peste de Marseille. 


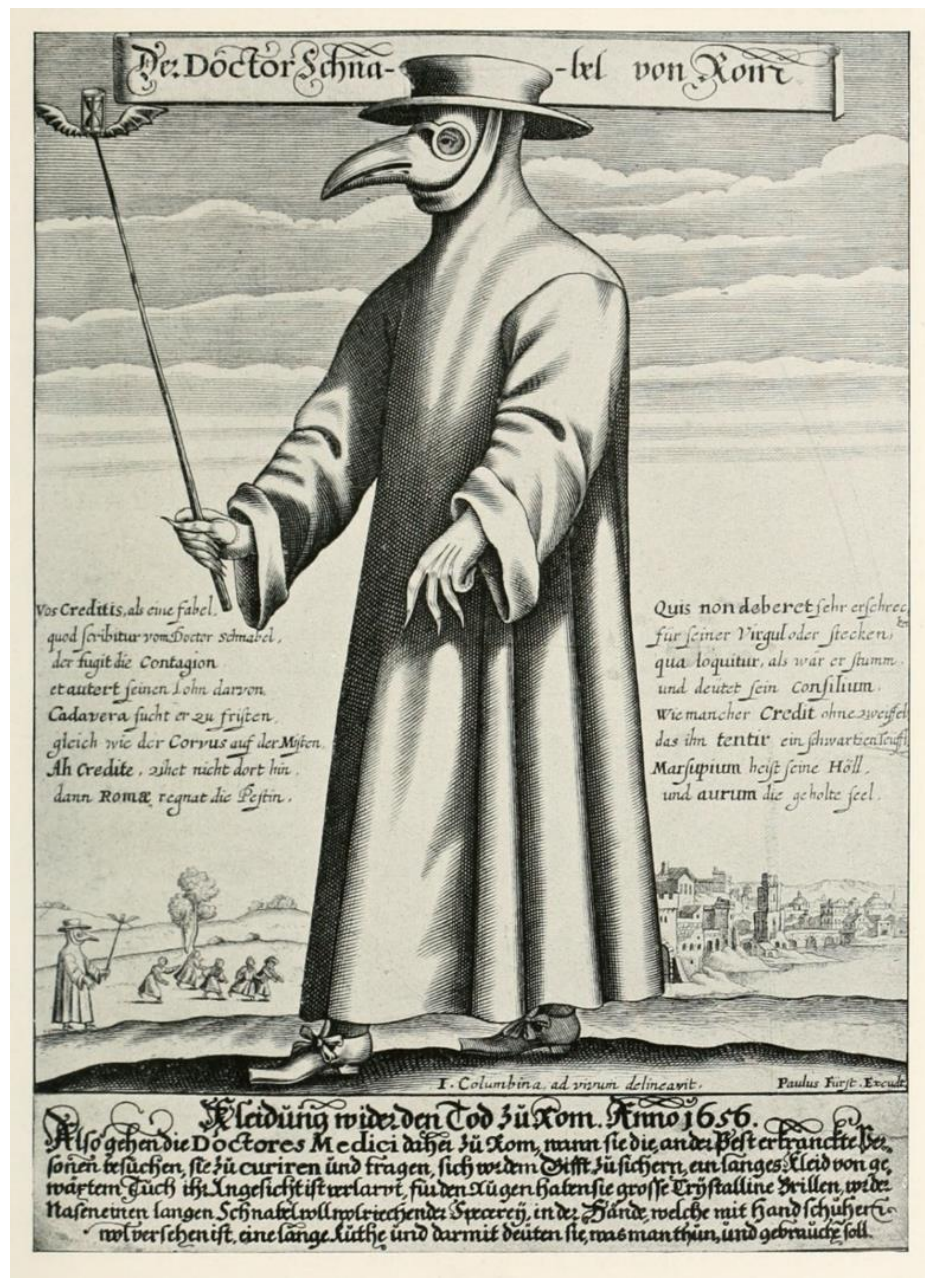

Ill. 2 : Le « Docteur-Bec» Chicoyneau

En 1722, elle inspira aussi au journaliste et romancier anglais Daniel Defoe une œuvre remarquable : son Journal de l'Année de la Peste (The Year of the Plague) ${ }^{10}$. Cette description de la catastrophe réunissait les informations parvenues deux ans plus tôt de Marseille et les souvenirs de la grande peste londonienne de 1664-1665, qui avait tué 70000 personnes. Defoe avait prédit l'épidémie de 1720 en remarquant dans son journal, Review, dès le 23 août 1712, que la peste progressait en Turquie, en Hongrie, en Pologne, en Suède, en Allemagne, au Danemark et qu'elle risquait donc de frapper d'ici peu les confins les plus occidentaux de l'Europe.

Localement, l'un des problèmes les plus urgents était posé par l'accumulation de cadavres en putréfaction, qu'on ne parvenait plus à porter en terre. Le Chevalier Nicolas Roze, commissaire du quartier de Rive-Neuve, parvint à les faire enlever par les soldats 
et les galériens, fossoyeurs improvisés qui tous moururent à la tâche, à l'exception de cinq, dont le Chevalier Roze.

Pendant ce temps, la peste de répandait dans les environs : Cassis, Aix, Toulon, Apt, Digne, Arles sont touchées à leur tour. A La Ciotat, où le gouverneur veut faire entrer la troupe, les femmes soupçonnent les soldats de leur apporter la peste et elles leur font barrage en brandissant devant elles leurs enfants. Entre Avignon et Sisteron, les autorités font élever le Mur de la Peste, construit en pierre, doublé d'un fossé et gardé par des soldats armés qui ont l'ordre d'arrêter, au besoin par la force, les fugitifs.

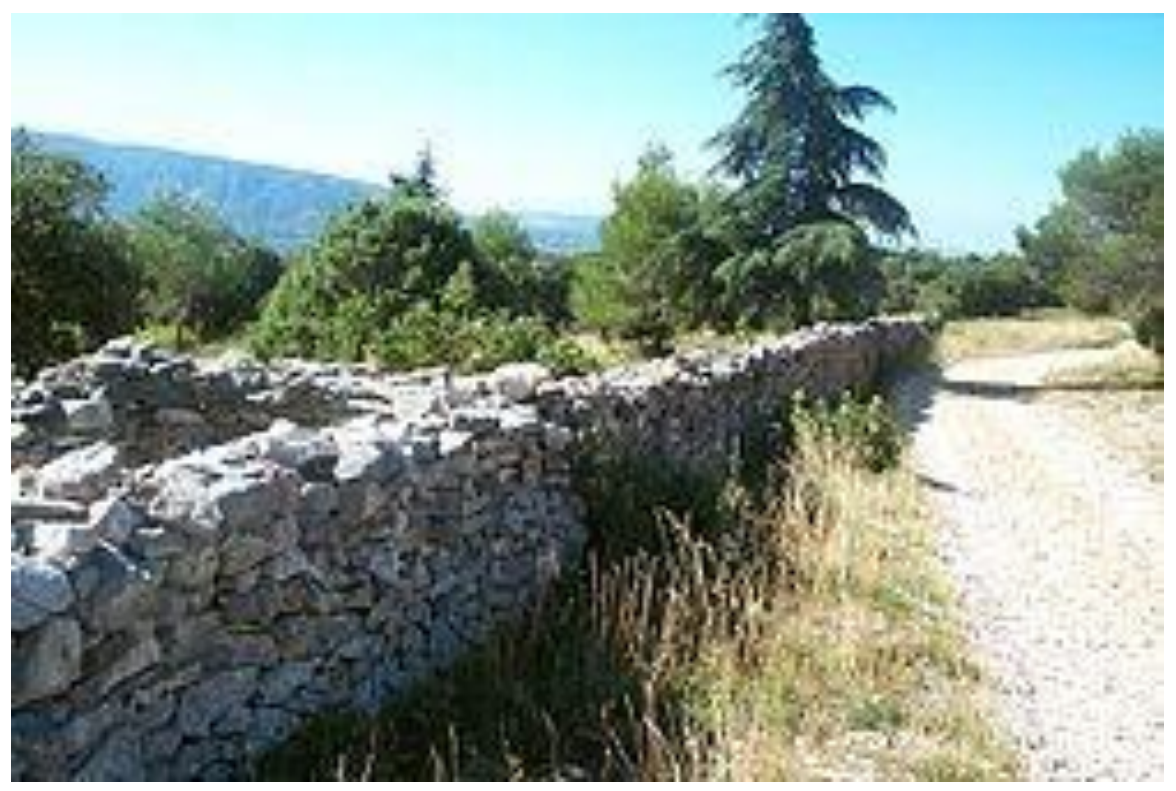

Ill. 3 : Vestiges du Mur de la Peste en Provence

Ailleurs, on se contente de disposer des « lignes » de soldats, afin d'empêcher les déplacements d'une région à l'autre. La « ligne » principale court tout le long du Rhône, mais elle échoue à cantonner la peste en Provence, sur la rive gauche : elle franchit le fleuve et se répand sur la rive droite, en Languedoc, dans les diocèses de Nîmes, d'Alès, d'Uzès et même de Mende plus au Nord. 


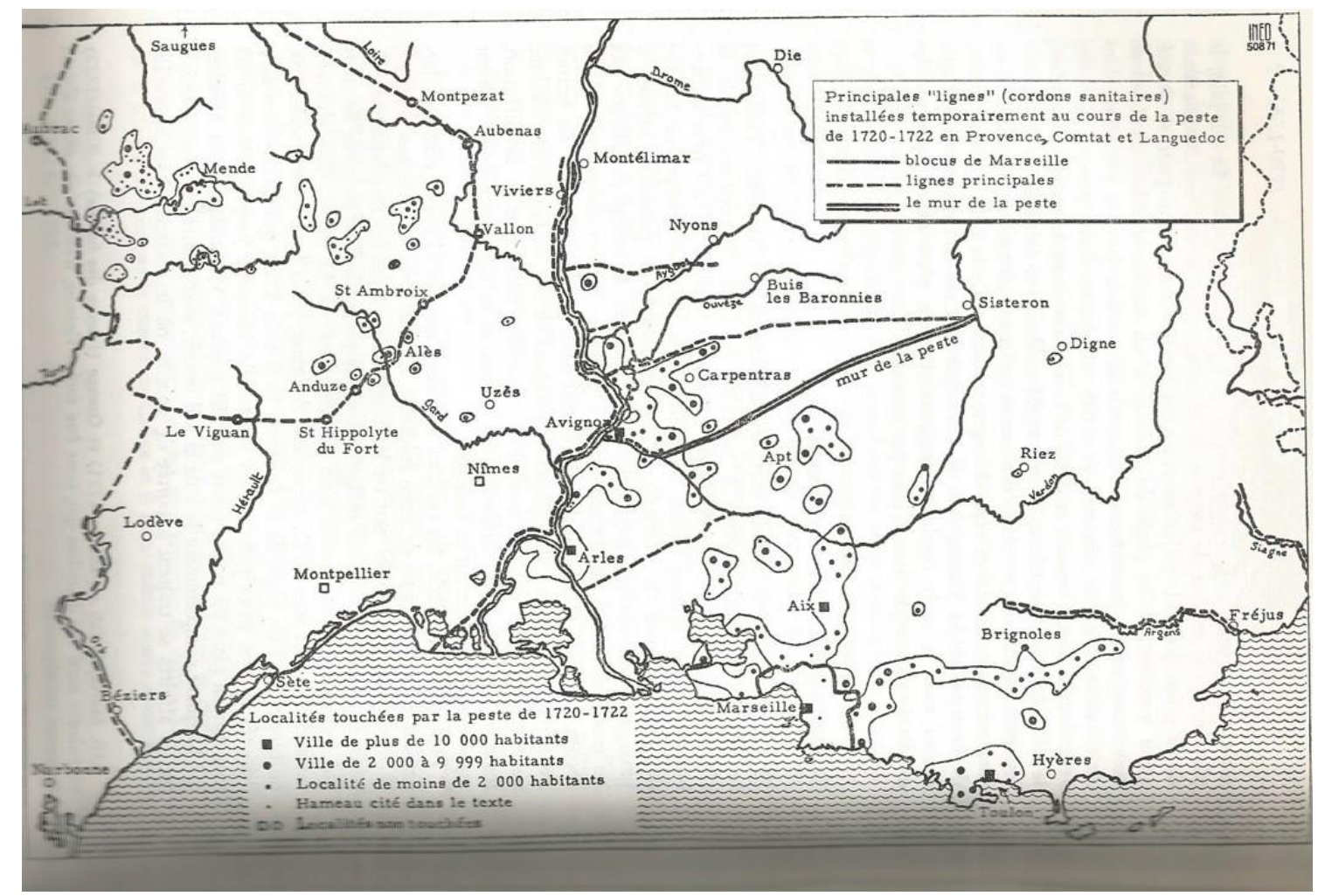

Ill. 4 : Carte de la diffusion de l'épidémie en Provence et Languedoc, d'après J.-N. Biraben, tome 1, p. 246

C'est à l'échelle micro-locale qu'on apprécie le mieux les aléas de la peste : les villes de Mende, Marvejols, La Canourgue (dans l'actuel département de la Lozère), sont sérieusement touchées : elles perdent environ un quart de leurs habitants. A côté de La Canourgue, la population du village de Corréjac, où un forçat enfui de Marseille s'est malencontreusement réfugié, est entièrement décimée et les maisons sont incendiées pour tenter d'éliminer la pestilence. En revanche, les villes proches de Villefort et Concoules, bien que situées sur l'axe de la Regordane (la route de Nîmes à Paris), ne perdent que $1 \%$ de leur population. Tout près de là, Genolhac (1100 habitants) déplore au contraire 250 morts (22, 7\% de la population). Mais l'épidémie épargne la vallée voisine du Luech où le village de Vialas, qui avait été si cruellement touché en 1348, est cette fois sauvé. On le voit, suivant le micro-réseau des voies de communication, leur fréquentation, la densité de la population et le degré de dispersion de l'habitat, voire même les hasards de la contamination, les ravages de l'épidémie varient énormément d'un lieu à l'autre, même à faible distance. 


\section{Les comportements collectifs face à la peste}

La peste est le mal absolu. C'est pourquoi elle est perçue comme le châtiment que Dieu inflige aux hommes pour les punir de leur péché. Elle est l'épreuve cathartique qui, pour certains, précède le combat final des forces du Bien et du Mal, la venue de l'Antichrist dont la défaite ultime permettra le retour du Christ et le Jugement dernier, tels que l'Apocalypse les a prédits ${ }^{11}$. C'est pourquoi les chrétiens doivent, à la faveur de la peste, se préparer à l'échéance eschatologique en invitant au repentir avant de succomber : la peste encourage les processions de pénitents et de flagellants et la création de confréries (telles celles des Pénitents Blancs et des Pénitents Noirs), placées sous le patronage de la Vierge Marie ou des principaux saints « anti-pesteux »: saint Sébastien (dont les flèches du martyre symbolisent l'attaque de la peste), saint Roch (qui porte sur la cuisse une paie assimilée au bubon de la peste) ou saint Antoine l'Ermite (traditionnellement invoqué contre le «Mal des Ardents» ou «Feu SaintAntoine »).

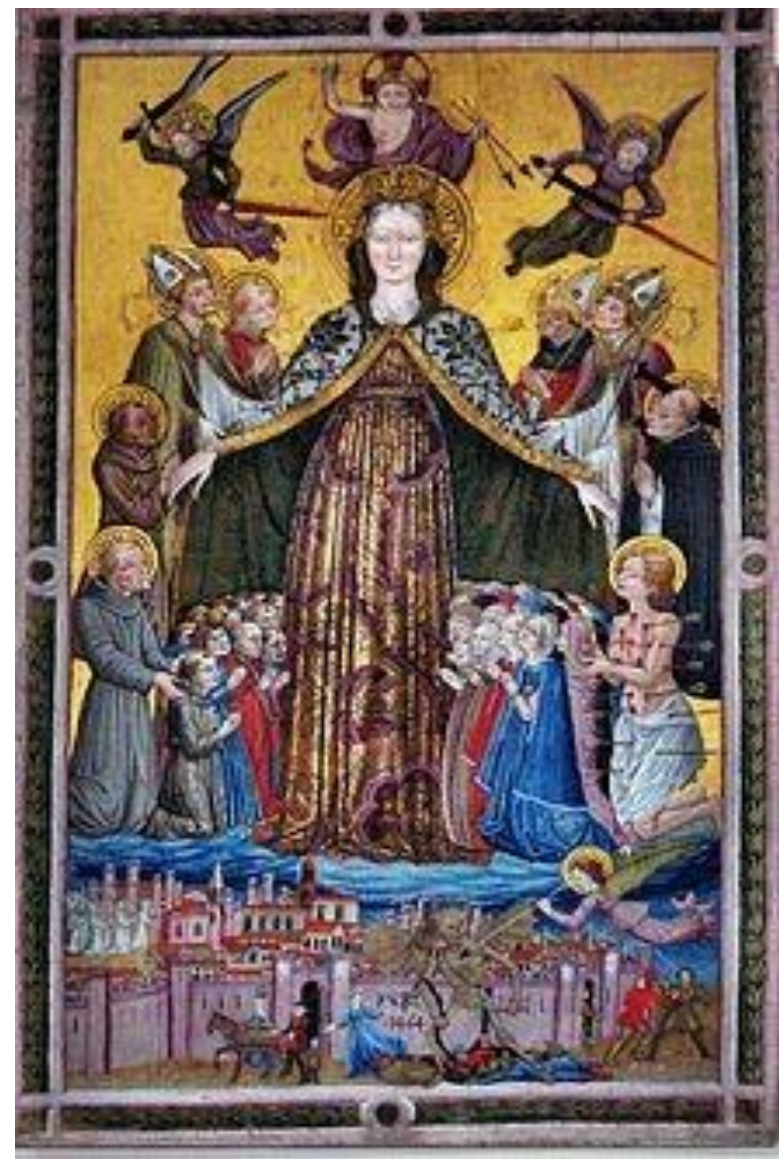

Ill. 5 : La Vierge de Miséricorde. Bannière processionnelle peinte par Beneditto Bonfigli, 1464, Perugia, Galleria Nazionale 
A l'époque moderne, les nouvelles expériences de la peste conduisent à ajouter à ce catalogue d'autres saints protecteurs, comme saint Charles Borromée. Après la peste de 1629, qui aurait tué « dix mille» habitants de la ville du Puy, les consuls de la cité firent un vœu solennel le 22 avril 1630 pour remercier Dieu et la « Glorieuse Vierge leur bonne dame et patronne » de les avoir délivrés du «mal de peste » : ils offrirent à la cathédrale deux grandes peintures, qui y sont aujourd'hui encore conservées ; sur l'une, les consuls sont représentés vêtus de rouge, en prière devant la statue de la Vierge Noire du Puy ; sur l'autre, où un cartouche explicite le vœu des consuls, est figurée la longue procession de tous les «ordres» de la cité, qui accompagnent la statue miraculeuse à travers la ville.

En 1348, le caractère soudain et massif de la Peste Noire conduit aussi à désigner des boucs émissaires. Dans le passé déjà, les catastrophes collectives, telles que la famine, la mort inexpliquée du bétail ou d'autres épidémies, avaient poussé la foule à accuser les pauvres, les mendiants, certaines femmes soupçonnées de maléfice et de façon générale tous ceux que ne bénéficiaient pas de la protection d'un solide réseau familial et social, d'avoir empoisonné les puits ou jeté un sort. Depuis le temps des croisades, les juifs avaient plus d'une fois fait l'objet d'une accusation de crimes rituels. Cette fois, ils sont tenus pour responsables de la peste et massacrés dans les villes où ils forment une part non négligeable de la population et où leurs activités lucratives de prêteurs à intérêt suscitaient traditionnellement hostilité ou jalousie. Les royaumes de France et d'Angleterre ne sont pas concernés puisque les communautés juives en ont déjà été chassées. En revanche, les villes du Rhin et de l'Allemagne du Sud-Ouest connaissent des scènes de violences épouvantables. A Strasbourg, le 14 février 1349, sur 1884 juifs, 900 sont massacrés et brulés. En Franconie, dans la région de Würzburg, un boucher du nom de Rindfleisch (sic) déchaîne contre les juifs une bande de tueurs sans pitié $^{12}$. Généralement, les autorités urbaines, ecclésiastiques ou souveraines (dont les juifs sont considérés traditionnellement comme les «serfs du Trésor » (Kammerknechtschaft) et qu'elles protègent pour en tirer d'autant plus de profits fiscaux et monétaires), cherchent à réfréner ces comportements. Le pape accueille les juifs à Avignon, comme le constate Thomas Platter, jeune médecin d'origine bâloise diplômé de l'Université de Montpellier, lorsqu'il visite la ville en 1598 : il rapporte la rumeur suivant laquelle les Juifs, qui ne consomment pas les viandes du derrière des bœufs, les 
vendent aux chrétiens après les avoir souillées et y avoir «jeté un sort pour que les chrétiens avalent la mort bubonique à l'aine. Tous ceux des juifs qui se sont convertis à la foi chrétienne ont attesté ce fait, à l'unanimité ${ }^{13}$. Même à Avignon, les juifs sont donc soupçonnés de répandre la peste. Un autre refuge est la Pologne du roi Casimir II, dont la politique d'accueil amorce un processus de refuge des communautés juives en Europe centrale qui prendra fin tragiquement avec la Shoa.

La peste oblige aussi à prendre des mesures de police générale et contribue ainsi au développement administratif des Etats et des villes à la fin du Moyen Âge. Dès le XIVe siècle, les villes italiennes prennent des mesures sanitaires d'intérêt public. A Venise sont nommés en 1348 trois " provéditeurs de santé ». La première ordonnance préconisant des mesures contre la peste à l'échelle de tout un royaume est promulguée par le roi de France Jean Le Bon en 1351. En 1429 est créée à Barcelone une commission ou cerca vouée à la recherche des pestiférés. En 1497, le Parlement de Paris intervient pour la première fois dans le domaine sanitaire. Dès 1383, à Marseille, on délivre aux voyageurs venant de villes non contaminées des «billets de santé ». En 1532, Londres inaugure la pratique des bills permettant aux individus d'attester qu'ils ne sont pas contagieux. Cette pratique est régulièrement observée en Languedoc à la fin du siècle, comme en témoigne Thomas Platter en 1598 : il ne quitte pas une ville sans demander un «billet de bonne santé » imprimé et certifié par les autorités de Nîmes, Uzès ou Montpellier ${ }^{14}$. Lors de l'épidémie de choléra en France en 1832, on parlera semblablement de «billettes » ${ }^{15}$. En 1668, une ordonnance royale statue sur la propreté de Paris en réglementant les dépôts d'ordures, en limitant la pollution des tanneries et des boucheries, en interdisant aux barbiers de donner à boire aux cochons le sang humain prélevé lors des saignées.

D'autres mesures visent à instaurer ce qu'on appelle aujourd'hui, à l'épreuve du Covid 19, des «gestes barrières »: la pratique de la quarantaine, dans les ports, se prévaut d'une idée déjà présente au VIe siècle $\mathrm{BC}$ chez le médecin grec Hippocrate, pour qui une maladie aigue se manifeste au plus pendant quarante jours, délai après lequel il ne s'agit que d'une maladie chronique. Cette période de quarante jours rencontrait un fort écho dans la société chrétienne, puisque le Christ avait jeûné tout ce temps dans le désert; l'Eglise suivit l'exemple en instituant le Carême (du latin quadragesima : quarantième), une période de pénitence de quarante jours avant la fête 
de Pâques. La première quarantaine maritime ou «quaranta » fut décrétée dans le port à Raguse en 1377 ; Venise, Marseille, Barcelone suivirent rapidement l'exemple. En complément de ces mesures furent créés des lazarets (le premier est attesté à Venise en 1374), destinés à isoler les malades du reste de la population : ils se révélèrent vite d'épouvantables mouroirs de masse.

Une autre mesure était «l'évitement», autrement dit la stricte fermeture d'une ville contaminée, en interdisant aux personnes saines d'y pénétrer. Inversement, une ville infestée, comme ce sera le cas de Marseille, était isolée du plat-pays par une « ligne » de défense solidement gardée. En Savoie, en 1575, on décréta ce que nous avons pris l'habitude de nommer le «confinement»: il fut interdit aux personnes de circuler en temps d'épidémie. Ailleurs, on procéda à la fermeture des écoles et les assemblées furent interdites. A Angers, le « baiser de paix » est prohibé dans les églises. Les autorités souveraines avaient seules le pouvoir d'établir des «lignes » et de la confier à la garde des soldats. Cette mesure est expérimentée à Paris par Colbert avant d'être généralisée, mais son efficacité, on l'a vu, était aléatoire. Les transfuges risquaient pourtant la fusillade. En 1722, le bureau de santé de Fréjus ordonna que soit fusillé le général Bonaparte, parce qu'il avait refusé de se soumettre à la quarantaine. Il en réchappa, ce qui ne fut pas sans conséquence pour l'histoire générale...

D'autres mesures avaient un caractère plus proprement thérapeutique. Les médecins sont sollicités, et souvent grassement payés en raison des risques encourus. Ils prescrivent que les malades soient enfermés chez eux, ou bien des dans des " cabanes » ou «loges », comme l'ordonne le pape Clément VI à Avignon dès 1348 ; ailleurs, ces enclos de fortune sont appelés « chabotes», « hobettes» ou simplement «tentes »si elles ont recouvertes d'une simple toile.

Outre les lazarets déjà mentionnés, on crée de nouveaux hôpitaux : à Paris, dans les faubourgs Nord de la ville, le roi Henri IV fonde 1'Hôpital Saint-Louis en 1607. A Lyon, trois nouveaux hôpitaux sont créés au confluent de la Saône et du Rhône, afin de pouvoir acheminer les malades par bateaux. D'anciennes léproseries (qui ne servaient plus guère étant donné la disparition de cette maladie à la fin du Moyen Âge) sont convertis en hôpitaux pour pestiférés. Il est difficile de parler de véritables soins donnés aux malades autres que l'assistance spirituelle. Crever un bubon d'un coup de scalpel ne suffit pas à guérir de la peste. 


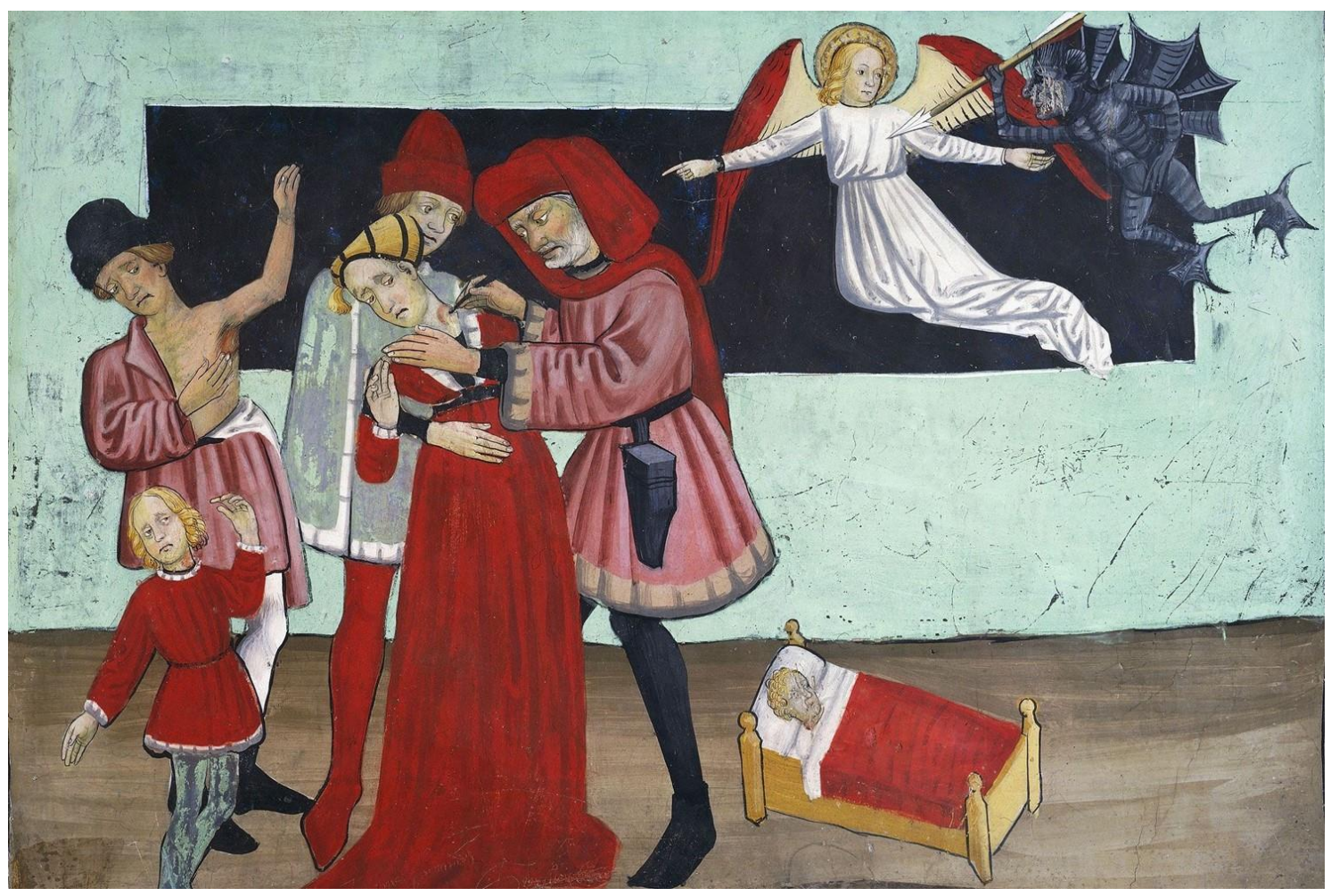

Ill. 6 : Un médecin crève les bubons dans une famille victime de la peste. Fresque du XVe siècle, chapelle Saint-Sébastien de Lanslevillard, Savoie

Le pire est que l'entassement facilite la contagion. Les taux de mortalité sont terrifiants et nul ne l'ignore : les malades préfèrent rester chez eux pour mourir. Mais dans ce cas, ils contaminent leur famille entière. En ville s'affairent les « parfumeurs », « désinfecteurs », « cureurs » ou " aéreurs », attestés dès le XVIe siècle. Ils pourvoient en encens, soufre, poudre à canon, arsenic, antimoine et autres substances susceptibles de purifier l'air pour faire barrage à la maladie. Mêmes les missives sont perforées afin de pouvoir y insuffler des parfums avant de les ouvrir. Aux XVIIe-XVIIIe siècles, la peur de la contagion joue un rôle dans l'engouement nouveau pour le tabac, que les hommes et aussi les femmes fument dans de petites pipes hollandaises en terre. Les médecins enveloppent leurs mains de feuilles de tabac avant de toucher les bubons. Du reste, le lien entre tabac et médecine ne se limite pas au cas de la peste, puisqu'à la même époque, à Londres comme à Paris, on pense pouvoir ranimer les noyés en leur insufflant de la fumée de tabac dans le fondement... ${ }^{16}$ 
L'un des points les plus cruciaux restait la collecte et l'enfouissement des cadavres, qu'il fallait tirer des maisons et ramasser ou plutôt « crocheter » en pleine rue. Les « corbeaux » ou « enterreurs » sont préposés à cette sinistre besogne, tandis que des femmes sont employées à « coudre les morts », c'est-à-dire à confectionner des linceuls. Pour ne pas provoquer de panique, il est interdit de sonner les cloches lors des enterrements et ceux-ci se déroulent de préférence la nuit. Incinérations massives et fosses communes sont nécessaires quand l'épidémie atteint des sommets. Le bouleversement des pratiques funéraires traditionnelles retient dès 1348 l'attention des contemporains. Il va conduire à terme à de nouvelles pratiques et en premier lieu, au début du XIXe siècle, à la relégation des cimetières en dehors des villes.

La peste a également stimulé de nouvelles pratiques administratives, encouragé les dénombrements de population, contribué à l'essor des statistiques publiques dans tous les domaines: le décompte des morts ou des orphelins n'est qu'un aspect du dénombrement de la population entière, de l'estimation de ses ressources, du calcul de la production de la consommation ou encore du recensement des indigents. Fortes de telles estimations chiffrées, les villes organisent l'approvisionnement en vivres et en parfums prophylactiques, la recherche de nourrices pour les orphelins (dès 1586, la municipalité de Grenoble fait élever un troupeau de chèvres pour les nourrir). Après 1720, celle de Marseille prend en charge 1300 nourrissons abandonnés.

La peste entraine aussi pour les gouvernants un manque à gagner fiscal, en raison de la chute drastique des contribuables. Les Etats tentent de compenser cette perte par une pression fiscale accrue sur les survivants : au temps de la peste succède ainsi celui des révoltes antifiscales, dont les exemples sont nombreux dans les années 1350-1380 : les Jacques en France, les Lollards en Angleterre (avec une composante religieuse particulière), les Tisserands de Gand, les Ciompi florentins, etc.

Une autre conséquence est le bouleversement du marché du travail. Après la peste, les ateliers et les chantiers manquent de bras et les salaires tendent à monter. Maîtres de métiers et autorités civiles tentent de freiner le renchérissement de la main d'œuvre. Ils dénoncent les «mendiants valides », les pauvres qui pourraient travailler de leur mains et préfèrent avoir recours à la mendicité ${ }^{17}$. Les Statutes of Labourers promulgués par le roi d'Angleterre entre 1349 et 1359, la Grande ordonnance de Jean II le Bon en 1351 déjà mentionnée, et ailleurs toute une série de textes semblables, témoignent de cette 
volonté de contenir le prix de la main d'œuvre au profit des patrons en mobilisant ce que Karl Marx nommait «l'armée de réserve de main d'œuvre ». Mais ces mesures n'ont eu qu'un effet limité. ${ }^{18}$

\section{Conclusions}

De 1348 à 1720, pendant près de quatre siècles, la peste a été une réalité permanente au cœur de l'histoire européenne. Elle n'a pas été présente toujours et partout à la fois comme en 1348, mais entre les agressions subites qui frappaient ici ou là à l'improviste et les retours plus ou moins réguliers qui en diminuaient l'effet de surprise, on peut dire que chaque homme, durant cette longue période, en a fait l'expérience une fois au moins dans sa vie. Et que beaucoup n'ont pas survécu à cette rencontre.

Les conséquences de la peste furent considérables, en premier lieu au plan démographique. Associée à une mortalité infantile déjà très élevée en temps normal et à une espérance de vie réduite pour ceux qui avaient la chance de dépasser l'enfance, elle a contribué à la stagnation de la population entre le début du XIVe siècle et le XVIIIe siècle. Au XVIIe siècle, le royaume de France, par exemple, compte « vingt millions de Français $»^{19}$, guère plus sans doute qu'à la fin du XIIIe siècle. Seules les révolutions médicales et hygiéniques des XIXe et XXe siècles, dont la victoire sur la peste sera l'un des acquis parmi d'autres, permettront de forcer les blocages démographiques structuraux de la période antérieure.

Aujourd'hui disparus et oubliés des populations européennes, les ravages passés de la peste ont laissé des traces matérielles, comme par exemple les quelques portions du Mur de la Peste, qui barra la Provence d'Ouest en Est en 1720. Plus anciens, les «villages désertés » attirent aussi l'attention des archéologues. C'est le cas du village médiéval de Rougiers, en Provence, qui fut l'occasion d'importants chantiers de fouilles archéologiques. Mais ces désertions n'ont pas nécessairement la peste pour seule raison : leur grand nombre en Angleterre est surtout dû à la politique des « enclosures » de l'aristocratie, qui n'hésita pas à chasser les paysans de leurs habitations et de leurs champs pour convertir les cultures vivrières en prairies vouées à l'élevage spéculatif du mouton, afin de pourvoir en laine les nouvelles manufactures drapières ${ }^{20}$. 
De l'histoire de la peste fait aussi partie l'évolution des conceptions de la maladie au fil du temps. De la conception «aériste » incriminant une corruption supposée de l'air et une perturbation des éléments, et de la crainte d'un châtiment de Dieu, on est passé à l'idée de la contagion, attribuée dans certains cas à un organisme vivant et minuscule, ce qui ouvrait la voie à la révolution pasteurienne et à la découverte décisive du bacille de la peste par Yersin en 1894. A cette date, la peste ne menaçait plus l'Europe directement. Entre temps, la lente maturation des conceptions «contagionistes" avait amené les autorités à prendre des mesures de protection (quarantaine, « lignes », blocus des villes, isolement des maisons et des personnes, etc.) qui ont pour une part permis d'éliminer le fléau avant d'en avoir identifié la cause réelle et d'avoir mis au point un sérum pour combattre le bacille. Notre situation face au Covid 19 est un peu plus avantageuse puisque le virus est identifié. Mais nous ne disposons toujours pas de vaccin pour le combattre. Ce qui n'interdit pas, bien au contraire, de s'entourer de moyens de protection, tels que les « gestes barrières ", le port du masque et la « quatorzaine » des personnes suspectes.

Un autre rapprochement entre les deux situations présentes et passées concerne la diffusion internationale de la maladie et la rapidité de sa propagation, même si cette dernière est naturellement bien plus véloce aujourd'hui en raison des moyens modernes de communication. Il faut souligner aussi que l'épidémie, dans le passé déjà, a favorisé le développement de l'information sur la progression du mal. Les villes italiennes s'en tenaient mutuellement informées dès le Moyen Âge. Les organes de l'Etat moderne en gestation faisaient le compte des provinces touchées et on a vu Louis XIV se soucier d'envoyer à Marseille une délégation d' " experts » ayant pour mission de lui rendre compte de la situation. L'information mutuelle est aujourd'hui une obligation de la communauté internationale et les Etats qui paraissent se soustraire à cette règle sont montrés du doigt.

Sans doute est-il trop tôt pour dire quelles productions littéraires et artistiques le Covid 19 laissera à la postérité. Son héritage littéraire sera-t-il aussi brillant que celui de la peste ? De Boccacio à Camus en passant par Defoe et bien d'autres, celle-ci peut en effet se prévaloir d'un beau palmarès littéraire. Mais il n'en alla pas de même dans le domaine des arts plastiques, comme si la sidération du fléau avait ici brisé l'élan créateur des artistes. On a dans le passé attribué à la Peste Noire la naissance de l'art 
macabre, qui expose complaisamment la décomposition des chairs et l'horreur du trépas. Mais la plupart des thèmes macabres de la peinture médiévale ou de la sculpture funéraire sont apparus avant la Peste Noire, ou bien se sont développés après elle, au temps des retours intermittents de l'épidémie et aussi bien d'autres fléaux aussi, si bien que des causes plus générales, sociales et culturelles, doivent leur être attribuées. Le Triomphe de la Mort et la Rencontre des Trois Vifs et des Trois Morts ont été peints au Campo Santo de Pisa par Buonamico Buffalmacco avant $1348^{21}$. La source littéraire qui a inspiré le deuxième thème pictural mentionné est quant à elle bien antérieure puisqu'il s'agit du Dit des Trois Vifs et des Trois Morts de Baudoin de Condé, vers 1240-1280 22.

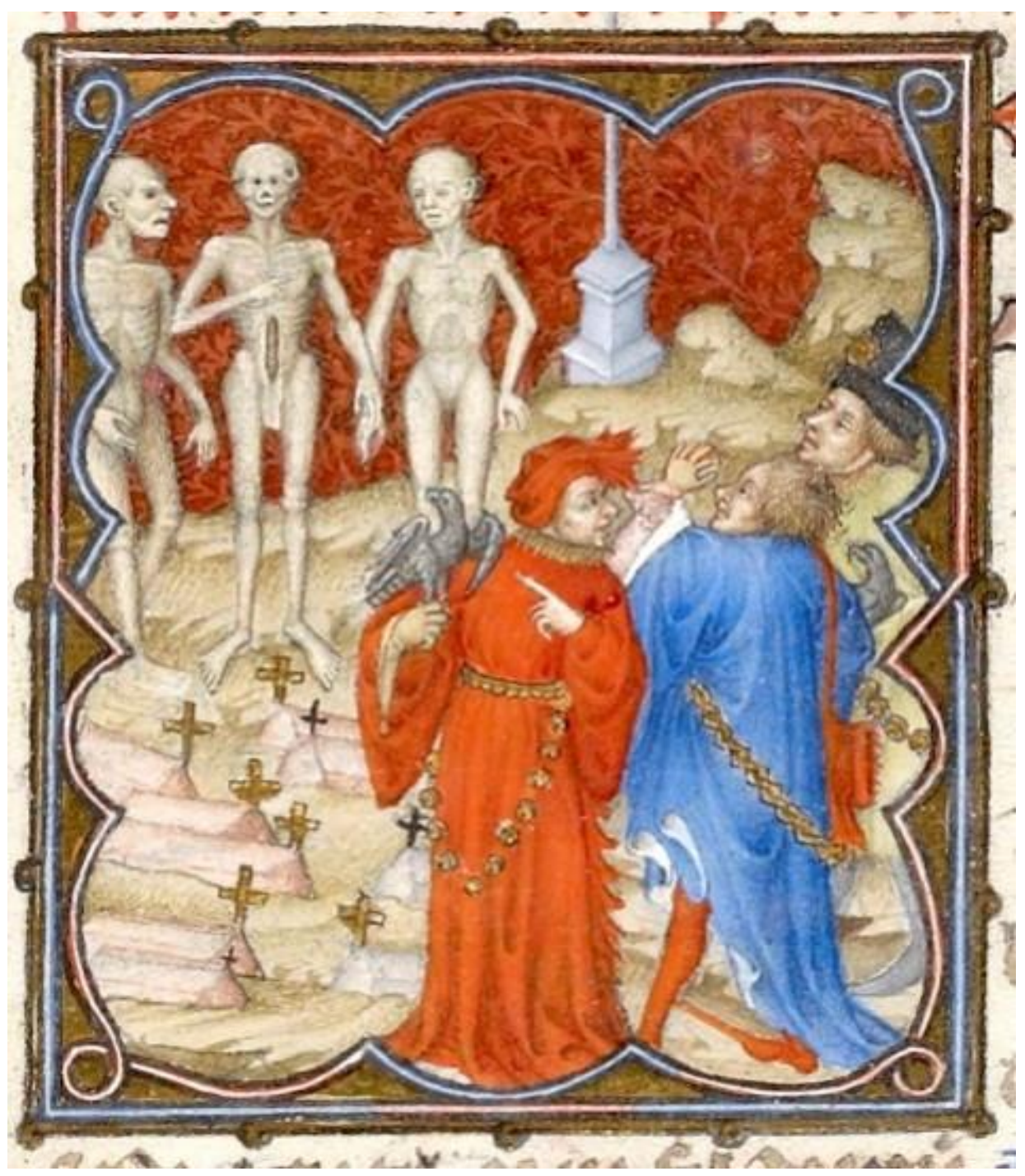

Ill. 7. Le Dit des Trois Vifs et des Trois Morts. Miniature d'un Livre d'Heures, XVe siècle 
Inversement, la Danse macabre n'apparaît pas avant le début du XVe siècle : sa première représentation, dans une des galeries du cimetière parisien disparu des Saints Innocents, date de 1424 ; on la connaît grâce aux planches gravées par Guyot Marchant en 1485

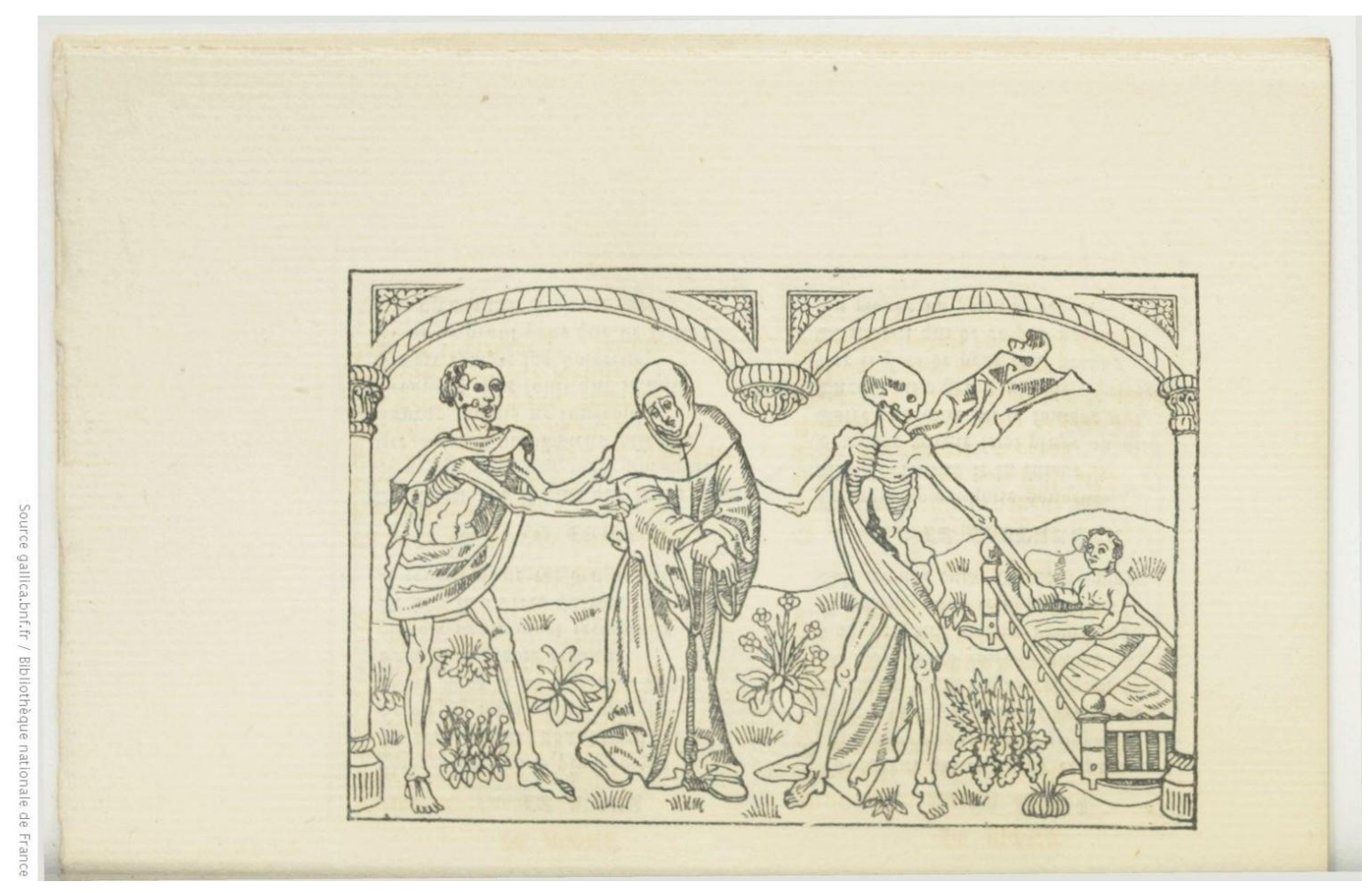

Ill. 8. La Danse macabre de Guyot Marchant, 1485

Il subsiste par ailleurs une cinquantaine de fresques du XVe siècle représentant le même thème dans des églises de France et d'ailleurs. Au final, les documents - ou plutôt les monuments - qui témoignent à chaud de l'agression pesteuse pourraient être assez rares. J'ai mentionné plus haut les deux tableaux peints de la cathédrale du Puy, qui sont des ex-voto publics. On peut leur comparer la Colonne de la Peste (Pestsaüle) érigée à Vienne en 1683 dans des circonstances semblables; elle fut imitée ailleurs en Autriche et en Allemagne du Sud pour commémorer les passages du fléau et le salut miraculeux de la population. 


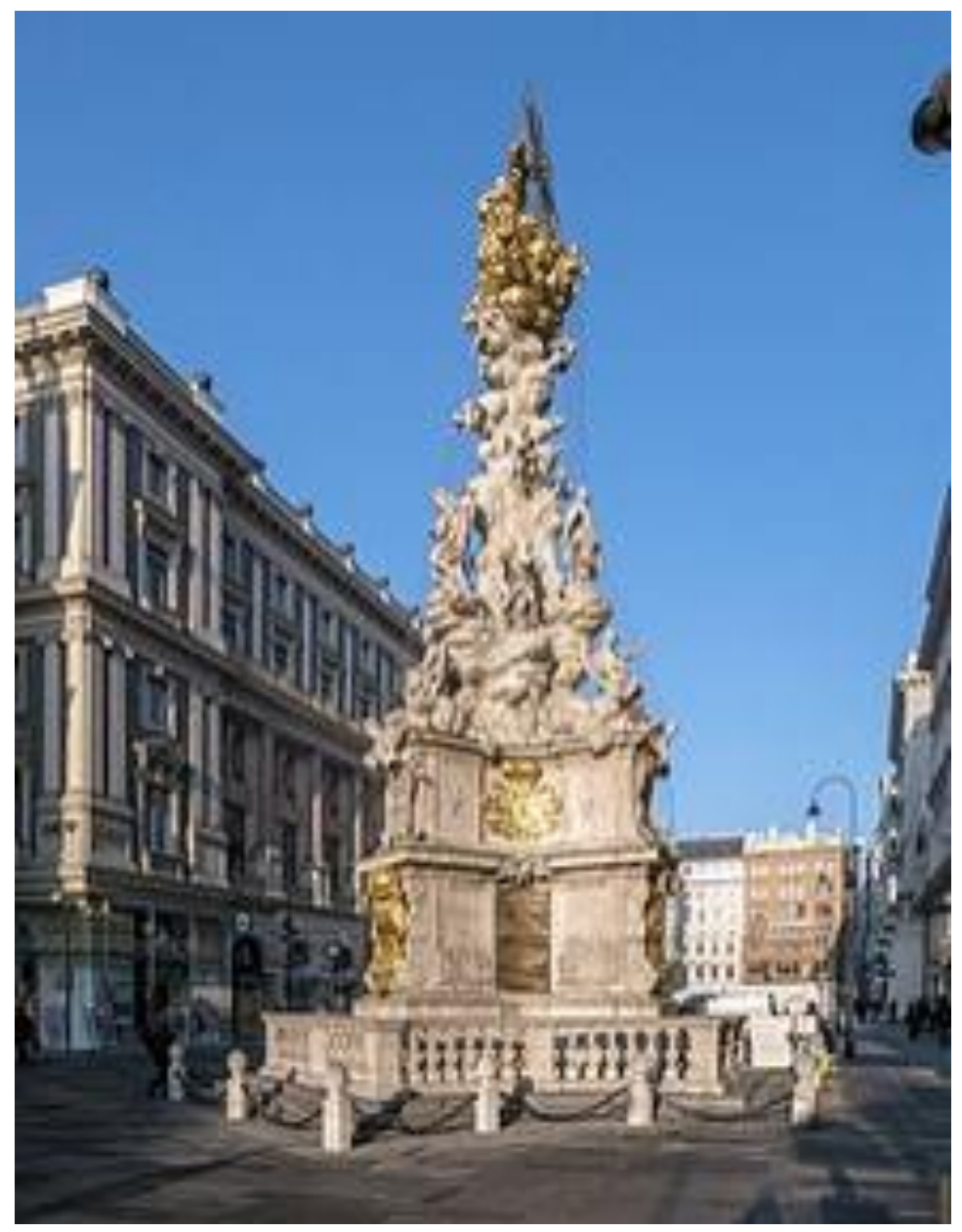

IIl. 9. Colonne de la Peste de Vienne, érigée sur le Graben en 1683

\section{Illustrations}

Ill. 1 : Carte de la diffusion de l'épidémie de peste en 1348-1352 (Wikipedia)

Ill. 2 : Le « Docteur-Bec » Chicoyneau et la Peste de Marseille en 1720 (Droits réservés)

Ill. 3 : Vestiges du Mur de la Peste en Provence (Wikipedia)

Ill. 4 : Carte de la diffusion de l'épidémie en Provence et Languedoc (J.-N. Biraben, tome 1, p. 246).

Ill. 5 : La Vierge de Miséricorde. Bannière processionnelle peinte par Beneditto Bonfigli, 1464. Perugia, Galleria Nazionale (Droits réservés). 
Ill. 6 : Un médecin crève les bubons dans une famille victime de la peste. Fresque du XVe siècle, chapelle Saint-Sébastien de Lanslevillard, Savoie. (Droit réservés)

Ill. 7. Le Dit des Trois Vifs et des Trois Morts. Miniature d'un Livre d'Heures, XVe siècle. (Droits réservés)

Ill. 8. La Danse macabre de Guyot Marchant, 1485 (Droits réservés).

I1l. 9. Colonne de la Peste de Vienne, érigée sur le Graben en 1683 (Wikipedia)

\section{BIBLIOGRAPHIE}

Jean-Noël BIRABEN, Les hommes et la peste en France et dans les pays européens et méditerranéens. Tome I: La peste dans l'histoire. Tome II : Les hommes face à la peste, Paris/ La Haye, Mouton, 1975 (Ecole des Hautes Etudes en Sciences Sociales - Centre de Recherches Historiques - Collection Civilisations et Sociétés, 35).

Guy Bois, Crise du féodalisme. Economie rurale et démographie en Normandie orientale du début du XIVe siècle au milieu du XVIe siècle, Paris, Presses de la Fondation nationale des sciences politiques, 1981.

Bruce M. S. CAmpbell, The Great Transition: Climate, Disease and Society in the Late-Medieval World », Cambridge, Cambridge University Press, 2016.

Albert Camus, La peste à Oran, Paris, Gallimard, 1947.

Hélène Dachez, «Peste, texte et contagion : Le Journal de l'année de la peste (1722) de Daniel Defoe », Dix-huitième siècle, 2015/1, n 47, p. 311 à 324.

Daniel Defoe, Journal de l'Année de la Peste. Trad. française par Francis Ledoux. Préface d'Henri Hubert Mollaret, Paris, Gallimard, 1982.

Paul Demont, "The Causes of the Athenian Plague and Thucydides", Thucydides between History and Literature, A. Tsakmakis, M. Tamiolaki (ed.), Berlin/Boston, De Gruyter, 2013, p. 73-87.

Dit des trois morts et des trois vifs. Éditions, traductions et études des versions médiévales (Essai de translatio collective), sous la direction de Claudio Galderisi, Pierre Nobel et Jean-Jacques Vincensini. Postface de Jean-Claude Schmitt (Bibliothèque de Transmédie. Études et Éditions, 6), Turnhout, Brepols, 2019. 
Michael Walters DOLS, The Black Death in the Middle East, Princeton, Princeton University Press, 1977.

Jean-Philippe Genet, « $\mathrm{A}$ propos de la « grande transition »: mesure et histoire :

$\begin{array}{llll}\text { Histoire } \quad \& \quad \text { mesure, } & \text { XXXII-2, }\end{array}$

(http://journals.openedition.org/histoiremesure/6295).

Jean Giono, Le hussard sur le toit, Paris, Gallimard, 1951. Erik A. Heinrichs, « The Live Chicken Treatment for Buboes: Trying a Plague Cure in Medieval and Early Modern Europe », Bulletin of the History of Medicine, 91, 2, Summer 2017, p. 210-232.

William Chester Jordan, The Great Famine. Northern Europe in the Early Fourteenth Century, Princeton, Princeton University Press, 1996.

Jacques Le Goff et Jean-Noël Biraben, «La peste dans le haut Moyen Âge », Annales E.S.C., XXIV, 1969, p. 1484-1510.

Emmanuel Le Roy Ladurie, Le siècle des Platter, 1499-1628. Tome 1, Le mendiant et le professeur. Tome 2, Le voyage de Thomas Platter, 1595-1599, Paris, Fayard, 2000. Millard Meiss, Painting in Florence and Siena after the Black Death: the arts, religion, and society in the mid-fourteenth century, Princeton University Press, 1978. Traduction française : La peinture à Florence et à Sienne après la peste noire : les arts, la religion, la société au milieu du XIVe siècle. Traduit de l'anglais par Dominique Le Bourg. Préface de Georges Didi-Huberman, Paris, Hazan, 2013.

«Pest », in Lexikon des Mittelalters, VI,, Munich, DTV, 2002, col. 1915-1921

Rudolf von Schlettstadt, Historiae memorabiles. Zur Dominikanerliteratur und Kulturgeschichte des 13. Jahrhunderts, hg. von Erich Kleinschmidt, Köln-Wien, Böhlau, 1974 (Beihefte zum Archiv für Kulturgeschichte, 10).

Anton Serdecny, Du tabac pour le mort: une histoire de la réanimation. Préface de Jean-Claude Schmitt, Ceyzérieu, Champ-Vallon, Coll. Epoques, 2018.

C.-E. A. Winslow and M.L. Duran-Reynald, « Jacme d'Agremont and the First of the Plague Tractates », Bulletin of the History of Medecine, 22, 6 (NovembreDecember 1948), p. 747-765. 


\section{Notas}

${ }^{1}$ Cet article développe la matière d'une conférence publique organisée par la municipalité de Vialas (France, département de la Lozère), le 13 août 2020.

${ }^{2}$ Cette notion a été proposée aux historiens de l'Europe par Jacques Le Goff.

${ }^{3}$ La meilleure étude d'ensemble de l'histoire de la peste en Europe reste celle de Jean-Noël BIRABEN, Les hommes et la peste en France et dans les pays européens et méditerranées. Tome I: La peste dans l'histoire. Tome II : Les hommes face à la peste, Paris/ La Haye, Mouton, 1975 (Ecole des Hautes Etudes en Sciences Sociales - Centre de Recherches Historiques - Collection Civilisations et Sociétés, 35). Je fais dans cet article de nombreux emprunts implicites à cet ouvrage.

${ }^{4}$ William Chester Jordan, The Great Famine. Northern Europe in the Early Fourteenth Century, Princeton, Princeton University Press, 1996.

${ }^{5}$ Bruce M. S. CAmpbell, The Great Transition: Climate, Disease and Society in the Late-Medieval World», Cambridge, Cambridge University Press, 2016. Voir le ompte-rendu de Jean-Philippe Genet, « À propos de la « grande transition »: mesure et histoire : Histoire \& mesure, XXXII-2, 2017 (http://journals.openedition.org/histoiremesure/6295), qui écrit notamment: «la pandémie s'est déclenchée non pas parce que Yersinia pestis est arrivée en Europe, mais parce qu'elle est arrivée en 1347, à un moment que les conditions climatiques ont rendu optimal pour sa diffusion ».

${ }^{6}$ Thucydide, La guerre du Péloponèse, livre II, « La peste d'Athènes ». Cf. Paul Demont, "The Causes of the Athenian Plague and Thucydides", Thucydides between History and Literature, A. Tsakmakis, M. Tamiolaki (ed.), Berlin/Boston, De Gruyter, 2013, p. 73-87.

${ }^{7}$ Guy Bois, Crise du féodalisme. Economie rurale et démographie en Normandie orientale du début du XIVe siècle au milieu du XVIe siècle, Paris, Presses de la Fondation nationale des sciences politiques, 1981.

${ }^{8}$ Je m'y suis même confiné durant l'épidémie de Covid 19 en 2020.

${ }^{9}$ Marie-Lucie Dumas, «Evolution démographique du Moyen Âge au XIXe siècle », in Vialas de la Cévenne au Mont Lozère, sous la dir. de M.-L. Dumas. Préface de Pauline Pantel et Jean-Claude Schmitt, Vialas, Le Filon des Anciens, 2019, 2 tomes, tome 1, p. 128. La population actuelle de ce village, après avoir atteint 2500 habitants au milieu du XIXe siècle en raison d'une activité minière et industrielle qui prit fin en 1894, compte aujourd'hui 450 habitants ... comme au lendemain de la Peste Noire !

${ }^{10}$ Daniel Defoe, Journal de l'Année de la Peste. Trad. française par Francis Ledoux. Préface d'Henri Hubert Mollaret, Paris, Gallimard, 1982. Voir Hélène Dachez, « Peste, texte et contagion : Le Journal de l'année de la peste (1722) de Daniel Defoe », Dix-huitième siècle, 2015/1, nº 47, p. 311 à 324.

${ }^{11}$ L'épidémie de Covid 19 suscite elle aussi des spéculations millénaristes qui ne sont pas sans rappeler celles du passé : voir les articles de presse de Joël E. Schnapp : https://www.lepoint.fr/debats/covid-19-etla-tentation-eschatologique-20-05-2020-2376334_2.php et https://www.lesinfluences.fr/Covid-19-vousreprendrez-bien-un-peu-d-Apocalypse.html

${ }^{12}$ Rudolf von Schlettstadt, Historiae memorabiles. Zur Dominikanerliteratur und Kulturgeschichte des 13. Jahrhunderts, hg. von Erich Kleinschmidt, Köln-Wien, Böhlau, 1974 (Beihefte zum Archiv für Kulturgeschichte, 10)

${ }^{13}$ Emmanuel Le Roy Ladurie, Le siècle des Platter, 1499-1628. Tome 1, Le mendiant et le professeur. Tome 2, Le voyage de Thomas Platter, 1595-1599, Paris, Fayard, 2000, t. II, p. 381.

${ }^{14}$ Ibid., p. 349. La formule de ces billets est toujours la même, telle par exemple celle-ci (Tome II, p. 349 "Nous, consuls de la ville de Nismes certifions estre parti dicelle, ou Dieu graces a bonne santé, monsieur Thomas Platter ce XII aoust 1598 pour aller a Uses. Le present ne servant que pour ung. Le XII aoust 1598. Rozel, consul » [Nous, consuls de la ville de Nîmes, certifions que Monsieur Thomas Platter est parti de cette ville pour aller à Uzès et qu'il est grâce à Dieu en bonne santé, ce 12 août 1598. Le présent certificat ne vaut que pour une personne. Le 12 août 1598. Rozel, consul.]

${ }^{15}$ Voir le roman de Jean Giono, Le Hussard sur le toit, Paris, Gallimard, NRF, 1951.

${ }^{16}$ Anton Serdecny, Du tabac pour le mort: une histoire de la réanimation. Préface de Jean-Claude Schmitt, Ceyzérieu, Champ-Vallon, Coll. Epoques, 2018.

${ }^{17}$ Je me permets de renvoyer à Jean-Claude Schmitt, Mort d'une hérésie. L'Eglise et les clercs face aux béguines et aux béghards du Rhin supérieur, Paris / La Haye / New York, Mouton Editeur / Ecole des Hautes Etudes en Sciences Sociales, 1978 (Coll. Civiliations et Sociétés, 56), p. 135-194.

${ }^{18}$ Bronislaw Geremek, Les marginaux aux XIVe et XVe siècles, Paris, Flammarion, 1976.

${ }^{19}$ Titre d'un essai célèbre de Pierre Goubert, Louis XIV et vingt millions de Français, Paris, Fayard, 1967.

${ }^{20}$ Rodney H. Hilton, «Villages désertés et histoire économique: recherches françaises et anglaises », Études rurales, n³2, 1968. pp. 104-109. 
${ }^{21}$ Millard Meiss, Painting in Florence and Siena after the Black Death: the arts, religion, and society in the mid-fourteenth century, Princeton University Press, 1978. Voirla traduction française et la préface éclairante de G. Didi-Huberman : La peinture à Florence et à Sienne après la peste noire : les arts, la religion, la société au milieu du XIVe siècle. Traduit de l'anglais par Dominique Le Bourg. Préface de Georges Didi-Huberman, Paris, Hazan, 2013.

${ }^{22}$ Le Dit des trois morts et des trois vifs. Éditions, traductions et études des versions médiévales (Essai de translatio collective), sous la direction de Claudio Galderisi, Pierre Nobel et Jean-Jacques Vincensini. Postface de Jean-Claude Schmitt (Bibliothèque de Transmédie. Études et Éditions, 6), Turnhout, Brepols, 2019. 